TEACHING AND LEARNING ETHICS

\title{
Practical virtue ethics: healthcare whistleblowing and portable digital technology
}

\author{
S Bolsin, T Faunce, J Oakley
}

See end of article for authors' affiliations .....................

Correspondence to: Associate

Professor Stephen N Bolsin, Barwon Health, Ryrie

Street, Geelong, Victoria,

Australia; steveb@

barwonhealth.org.au

Received

16 September 2004

In revised form

4 January 2005

Accepted for publication

7 January 2005
J Med Ethics 2005;31:612-618. doi: 10.1136/jme.2004.010603

Medical school curricula and postgraduate education programmes expend considerable resources teaching medical ethics. Simultaneously, whistleblowers' agitation continues, at great personal cost, to prompt major intrainstitutional and public inquiries that reveal problems with the application of medical ethics at particular clinical "coalfaces".

Virtue ethics, emphasising techniques promoting an agent's character and instructing their conscience, has become a significant mode of discourse in modern medical ethics. Healthcare whistleblowers, whose complaints are reasonable, made in good faith, in the public interest, and not vexatious, we argue, are practising those obligations of professional conscience foundational to virtue based medical ethics. Yet, little extant virtue ethics scholarship seriously considers the theoretical foundations of healthcare whistleblowing.

The authors examine whether healthcare whistleblowing should be considered central to any medical ethics emphasising professional virtues and conscience. They consider possible causes for the paucity of professional or academic interest in this area and examine the counterinfluence of a continuing historical tradition of guild mentality professionalism that routinely places relationships with colleagues ahead of patient safety.

Finally, it is proposed that a virtue based ethos of medical professionalism, exhibiting transparency and sincerity with regard to achieving uniform quality and safety of health care, may be facilitated by introducing a technological imperative using portable computing devices. Their use by trainees, focused on ethical competence, provides the practical face of virtue ethics in medical education and practice. Indeed, it assists in transforming the professional conscience of whistleblowing into a practical, virtue based culture of self reporting and personal development.

\footnotetext{
C
} onsiderable resources are expended worldwide teaching and promoting the principles of medical ethics in university curricula and postgraduate continuing education programmes. Although they are often poorly emphasised in the published literature, at the normative foundations of the dominant principlist system of medical ethics are professional virtues, such as loyalty to the relief of patient suffering, honesty, empathy, and competence, all linked with and emphasising the importance of conscience in professional life. These professional virtues, as well as their related principles, find direct or implicit expression in the Geneva Declaration (or modern reformulation of the Hippocratic Oath) and the International Code of Medical Ethics, and should be further emphasised in the UNESCO Universal Bioethics Declaration.

Whistleblowers, commonly stating that they are motivated by professional conscience and virtue to apply principles of medical ethics, health law, or international human rights, continue, at great personal cost and surprisingly little positive institutional or collegial acknowledgement, to reveal significant problems with the quality and safety of health services. ${ }^{1-4}$ Their allegations have almost invariably been proven, by subsequent, costly public inquiries, to have revealed inappropriate institutional cultures of professionalism, as well as significant deficiencies in how the principles of medical ethics are consistently applied at the clinical "coalface". ${ }^{4-6}$ Healthcare whistleblowing encompasses a range of activities, from honesty to individual patients about minor errors hitherto undisclosed, to public revelations (justified by reference to socially acceptable principle) of previously suppressed large scale institutional incompetence.
In this article we examine whether principlist perceptions of medical ethics by senior clinicians, and a reluctance to incorporate whistleblowing within virtue based approaches, may be promoting an ethics of "getting away with it" and an informal counterethics and proguild mentality curriculum. Such a proguild mentality has traditionally been embedded in the medical professional hierarchy and has involved a routine disjunction between ostensible ethical knowledge and integrity until such time as public attention is focused on a particular situation. ${ }^{7-10}$

We then consider whether healthcare whistleblowing should be presumed to be a valid manifestation of a system of medical ethics emphasising virtue and conscience. We conclude by following the implications of earlier work on the theoretical foundations of healthcare whistleblowing ${ }^{11}$ in considering whether widespread utilisation of portable digital technology, focused on improving ethical competencies, may create a technological imperative for transforming the professional virtues and conscience, which underpin acts of healthcare whistleblowing, into an active culture of self reporting and personal development.

\section{MEDICAL ETHICS'S PERPLEXING HISTORICAL RELATIONSHIP WITH COLLEGIAL CRITICISM}

Contemporary medical ethics has yet to develop a firm theoretical conception of what has come to be known as "whistleblowing" in health care. ${ }^{11}$ This is despite the fact that those involved in healthcare whistleblowing are now considered by many to be great exemplars of a practical virtue based approach to the application of the norms of medical ethics. ${ }^{4512}$ Whistleblowing may be defined for 
present purposes as the attempt, in good faith and in the public interest, to disclose and resolve in a reasonable and non-vexatious manner, but in the face of significant institutional or professional opposition, a significant deficiency in the quality or safety of health care.

One way to begin to gain insights about why whistleblowing, as defined above, should continue to create such angst among medical educators and professional regulators is to examine some salient points in the traditionally accepted regulatory history of the medical profession. Perhaps we may find here evidence about why individuals motivated chiefly by conscience and professional virtue to make decisions in the interests of patient safety appear to have come regularly into conflict with those who saw medical ethics as primarily a device to preserve the professional status quo, their incomes, and their social status.

Medicine was probably first referred to as a "profession" in the Western world by Scribonius Largus in the first century $\mathrm{AD}$ in his treatise Compositiones Medicamentorum (On Remedies)..$^{13}$ In this historical period, the act of "professing" in public an allegiance to basic virtues, such as honesty, purity, and even holiness, appears designed to produce a longlasting impact on the shape and content of a practitioner's clinical conscience. ${ }^{14}$ Yet, nothing approaching what we now define as whistleblowing appears to have been mentioned. Perhaps the simple truth is that there was then no genuine objective standard against which one physician could critique the work of another.

By the late 1600s, empirical physicians such as Thomas Sydenham and Ambrose Paré were practising in a manner that indicated they preferred to close their volumes of Galen and open their eyes to look at the patient as a real person. ${ }^{13}$ This gradual influx of scientific objectivity began to create objective standards of quality and safety. Yet, written exhortations to professional virtue, and obedience to ethical rules, in this age related mostly to matters of correct etiquette and treating colleagues with respect. This was vital, many considered, if a doctor was to financially exploit the monopoly privileges the state had granted his profession. ${ }^{15} 16$

That great medical iconoclast, Dr Gideon Harvey, frequently and openly referred to the Royal College of Physicians as "the eldest quack synagogue". ${ }^{17}$ He derided their public expressions of virtue as hypocritical and self serving. It appears that Harvey's motivations for such criticisms did not relate solely to personal lack of advancement, but arose from a virtuous desire to assist patients. If so, then elements of what are now termed whistleblowing may be ascribed to them. For his pains, Gideon Harvey suffered what, sadly, has become the standard professional response: being ostracised. ${ }^{12}{ }^{18-21}$

By the 19th century, the "Hippocratic Oath", with its strange deities and quaint references to virtues such as "holiness" of life, was considered too general and imprecise to accurately represent the core ideals of the profession. Those in charge of the institutions of medicine saw a need for more explicit ethical rules of professional conduct if prestige was to be maintained and patient trust justified. John Gregory (1725-1773), Benjamin Rush (1746-1813), and Thomas Percival (1740-1804) made significant contributions to this codification project. ${ }^{22}$ Gregory's Lectures on the Duties and Qualifications of a Physician, published in Edinburgh in 1772, developed a prototype ethical rule of truth telling during terminal illness. ${ }^{15}$ This monograph had little to say about professional virtues and nothing that even vaguely resembled an obligation to champion the safety of patients ahead of relationships with colleagues. One possible reason for this is that diminishing the role of the former inhibited challenges against the latter.
Percival was an English physician who, in 1803, published a work entitled Medical Ethics or a Code of Institutes and Precepts Adapted to the Professional Conduct of Physicians and Surgeons. ${ }^{23} \mathrm{He}$ was a close friend of Thomas Gisborne, an ecclesiastical writer who was concerned that medical professionalism might subvert common fellowship and Christian charity. ${ }^{24}$ Percival's code held that a doctor's conscience was the "only tribunal" and that his responsibility was to learn from his mistakes and make sure they did not recur. ${ }^{23}$ Nevertheless, his code also contained no reference to the need for a virtuous colleague to restrict the activities of impaired colleagues in the public interest.

It became fashionable for American medical societies to append codes, derived from writings such as those of Gregory, Rush, and Percival, to their constitutions. The first two chapters of Percival's book were used as the basis of the influential American Medical Association's Code of Ethics in 1847.22

It would be wrong now to regard every form of criticism of the profession, or one of its members, by a colleague as whistleblowing. Yet, this may be as close as we come to an historical antecedent in the 19th century-for example, in 1849 Hooker published a monograph entitled Physician and the Patient or a Practical View of the Mutual Duties, Relations and Interests of the Medical Profession and the Community. ${ }^{25}$

Hooker criticised the regulatory efforts of the medical profession to date, saying it had been more concerned with "the science of patient getting" than to the neglect of "the science of patient curing". ${ }^{25}$ When Jukes Styrap offered his Code of Medical Ethics to the British Medical Association in 1882 to use as the basis of an ethical code, the BMA closed ranks, implying such an action would infringe their guild type "closed shop" professional culture. ${ }^{26}{ }^{27}$ This may be an important point, given frequent subsequent allegations by contemporary healthcare whistleblowers of the profession's "hidden curriculum" that routinely opposes their efforts.

The earliest efforts to monitor and critique the performance of healthcare systems, in a manner resembling contemporary quality and safety approaches, were undertaken by figures such as Florence Nightingale, ${ }^{28-30}$ Ernest Amory Codman in Boston, and Lord Moynihan in Great Britain. ${ }^{31}{ }^{32}$ The application of some form of statistical analysis to early measures of activity in hospitals was an important feature of this pioneering work. ${ }^{28} 29$ Codman coined the phrase "end result" to try to quantify the outcome of the hospital episode and is hailed as a medical pioneer of current moves toward evidence based medicine. ${ }^{31}$ These early efforts to measure objectively the effectiveness of hospitals and doctors in diagnosing and treating illness were not well received and Codman was shunned and excluded from medical practice in Boston. ${ }^{33} 34$

The introduction of risk adjustment that followed the improvement in statistical methods that occurred after the second world war significantly enhanced the process of outcome analysis. Dr Mark Chassin in New York State was able to undertake a series of mandatory data collections in cardiac surgery and other surgical and medical specialties. These analyses achieved a level of sophistication that allowed them to identify the contribution of not only patients but also individual clinicians to adverse surgical outcomes as well as quantifying the contribution of institutions to those adverse outcomes. ${ }^{35}{ }^{36}$ Although their emphasis was on the numbers in a series, along with crude measures of outcome, these pioneers of risk adjustment and clinical governance were frequently castigated by their colleagues, much as healthcare whistleblowers are now. ${ }^{12412} 37$

Perhaps the most iconic figure among the pantheon of what may be termed healthcare whistleblowers was Dr Ignaz Semmelweis. Semmelweis was a law student who switched 
to study medicine. He is still widely respected for his strength of character and professional virtues in attempting to implement the principle of beneficence declared in the Hippocratic Oath. ${ }^{38}$ The story is now well known but worth summarising. As a house officer at the Vienna General Hospital obstetric clinic, he noted that the autopsy of a colleague, who died after accidentally cutting his finger during a postmortem examination, seemed to reveal the same septic pathology as the women dying of puerperal fever. Semmelweis hypothesised that medical students and junior doctors who had recently examined either corpses in the morgue or infected surgical wounds could somehow be spreading disease. ${ }^{39}$

His uncompromising stance, that doctors could be spreading disease from their hands and should wash them, was met with the type of professional outrage, abuse, and attacks on his own competence that has become almost the typical initial response to a contemporary healthcare whistleblower. ${ }^{40}$ Semmelweis was not reappointed, had to take an unpaid midwifery instructorship, then was sacked from that post. His successor abolished his guidelines as "ridiculous". ${ }^{41}$ The great Rudolph Virchow spoke out against Semmelweis's ideas at an international conference. Semmelweis responded: "I am linked to you by many pleasant memories, but the groans of women dying in childbed drown out the voice of affection". Semmelweis, despite the fact that he appeared to have sincerely striven to uphold the basic canons of the Hippocratic Oath, ended life alone and greatly disturbed in mind. He was beaten to death by the staff of a mental hospital in which he was incarcerated. ${ }^{18}$

In many ways it is only a short journey from Semmelweis to the professionally induced tribulations of healthcare whistleblowers in, for example, the United Kingdom, the US, Canada, and Australia. ${ }^{1-5}{ }^{37}$ The foundational emphasis on professional virtue and conscience and ethical principles related to them, accompanied by the disregard of healthcare whistleblowers who honestly seek to shape their characters by actions so motivated, remains a perplexing conundrum at the heart of contemporary medical ethics.

\section{WHISTLEBLOWING AND THE COUNTERETHICS CURRICULUM}

Whistleblowers have been the driving force behind a series of recent major contemporary public inquiries that have clearly identified significant deficiencies in institutional healthcare quality and safety. Without exception the final reports of such inquiries have ascribed blame, at least partially, to local professional cultures where senior clinicians were deficient in practical application of medical ethics. Notable examples include the Bristol Royal Infirmary Paediatric Cardiac Surgery Inquiry, ${ }^{42}$ the Winnipeg paediatric cardiac surgery scandal, ${ }^{5}$ the Campbelltown, Camden, Mt Druitt, and Canberra Hospital inquiries, ${ }^{43}$ and the Inquiry into Gynaecological and Obstetric Services at King Edward Memorial Hospital. ${ }^{4}$ Revelation of these scandals has allegedly shocked the public and ostensibly surprised the profession. In this context it remains perplexing that medical ethics has not made greater attempts to incorporate healthcare whistleblowing into a theoretical structure increasingly emphasising agent centred, character driven, or virtue based approaches. ${ }^{40} 44-49$

Goldie et al recently published a very disturbing analysis, from the virtue ethics point of view, in the journal, Medical Education. ${ }^{9}$ Their data showed that when medical students were challenged with identical ethical scenarios in the first and last weeks of a four year medical training course, the number making an ethically "correct" decision was unchanged at $40 \%$. Even worse, the percentage of students confirming they would actually report the unethical behaviour declined from a high of $13 \%$ in the early weeks to a low of $<5 \%$ in the last weeks of training. The likely cause of such a decline in what may be termed "whistleblowing" is the "hidden curriculum" communicated to students through the actions, attitudes, and comments of senior clinicians encountered in clinical rotations. ${ }^{3}$

The phrase "hidden curriculum" was coined by Hafferty and Franks in 1994. It was used to describe a powerful institutional culture, which, in practice, subverted and contradicted, the fundamental ideals of medical ethics. ${ }^{7}$ Wolf et al had already described a similar process through a retrospective study of attitude change during medical education in $1989 .^{50}$ Hundert and colleagues in 1996 likewise outlined an informal ethics curriculum acting against the formal ethical training in undergraduate medicine. ${ }^{8}$

Rennie and Crosby had suspected such a cause for their findings that medical students become worse rather than better at correct ethical decision making as medical training progresses. ${ }^{51}$ Goldie and Schwartz confirmed these findings. ${ }^{51}$ The "hidden curriculum" explanation suggests that as these students begin to have greater exposure to doctors who are poor role models of professional virtue they consistently fail to apply ethical principles in their work. If this is true the obvious question is 'can anything practical now be done about this erosion of commitment to ethical standards, this lack of appreciation of those who whistleblow in the interests of patient safety?'.

\section{WHISTLEBLOWING'S FOUNDATIONS IN VIRTUE ETHICS}

Most recent work in virtue ethics emphasises the character of the agent as a crucial addition to knowledge about principles, rules, and duties, as well as the consequences of their performance or non-performance. Proponents of virtue ethics also commonly focus on an agent's motive, emotion, and whole "plan of life", as well as isolated moments of choice and discrete actions.

Consistent adherence to, or a disposition to act in accordance with, relevant and authoritative principles and rules does not alone constitute virtue according to most virtue ethicists. Also crucially required are the appropriate motive and emotions. ${ }^{52}$ According to the generally accepted tenets of virtue ethics, a health professional acts rightly when he or she does what a virtuous agent would have done in the circumstances. Also, on the traditional Aristotelian account, a virtuous agent is someone whose will to consistently apply principle has cumulatively developed traits of character that enable him or her to live an exemplary human life, which displays their conscience, wisdom, temperance, courage, integrity, self knowledge, justice, and capacity for friendship. This is generally, if inaccurately, presented as a contrast to (rather than a foundation of) Kantian approaches to ethics, which instruct agents to act in accordance with universally applicable rules, or utilitarian reasoning, which dictates that agents should maximise human benefit and minimise its harm.

Applied to the healthcare setting, the requirement of virtue ethics that a physician, for example, should embody integrity, necessitates that he or she is prepared to consistently act on socially and professionally approved principles, even in the face of contrary forces and difficult circumstances. Integrity counts as a virtue, not because it is warranted by some generally applicable rule or because it maximises utility, but because humans operating in this setting cannot live and work well without it. A doctor, for instance, who was thoroughly lacking in the professional virtue of integrity might be able to amass significant material wealth, but he or she would have great difficulty living a flourishing life in a 
manner characteristic of a fully expressed and valued human being.

One way of shaping virtue ethics scholarship so that it becomes more systematically responsive to the acts of whistleblowers in the clinical practice of medicine can be outlined as follows. A virtue ethics approach to healthcare whistleblowing could begin by determining what counts as acting well in the context of such a professional role. This could be assessed by looking not only at how well that role functions in serving the goals of the profession, but by how those goals are connected with the broader social activities as reflected in norms of jurisprudence and international human rights. That is, it would be institutionally emphasised that good professional roles must be part of a good profession, and a good profession is one that involves a commitment to a key human good, without which humans generally cannot flourish. Further, although a certain profession itself may meet these requirements, it must also be possible to demonstrate how the particular role under scrutiny contributes to the overall goal of the local and international community.

For example, if it were appropriate to take healing as a central goal of medicine, then, given the importance of health for human flourishing, medicine should presumptively count as a good profession in terms, for instance, of the foundations of law and international human rights, as well as medical ethics. Similarly, given a general practitioner's concern with the broad health needs of its patients, the general practitioner's role within medicine should count as a good professional role regardless of which normative system was applied. Thus, in order to generate a defensible professional ethic, from a virtue ethics perspective, the norms of the profession in question cannot simply be taken as given, as a matter of self regulation; rather they must be shown to reflect a commitment to one or more of the substantive human goods, which are important constituents of a flourishing human life.

Virtue ethics approaches to whistleblowing in medical practice would examine issues in patient care by looking at the doctor/patient relationship, and the sorts of character traits that are crucial for those in medical practice to flourish: conscience, wisdom, temperance, honesty, compassion, integrity, and justice. On this approach then, doctors ought to tell the truth to patients, not so much (as the caricature principlist version of Kantian reasoning would dictate) because of the importance of informed consent and respect for patient autonomy, nor (as utilitarian reasoning would maintain, because patients generally do better if they are well informed about their condition but because that is what is involved in a doctor having the virtue of truthfulness. ${ }^{53}$

Virtue ethics is actually well suited to providing a normative foundation for healthcare whistleblowing. Reporting unethical colleagues is an expression of the professional virtues of integrity and conscience, the moral significance of which is much better encapsulated conceptually by the normative system of virtue ethics when an attempt is made to integrate it with principlist or utilitarian reasoning. ${ }^{54}$ Integrity and conscience are essentially functions of the character that one determines to display in acting, and each can have both personal and professional dimensionsfor example, in medicine, acting with professional integrity and conscience means not just deliberating upon, but implementing, principles from a commitment to the proper goals of medicine, such as loyalty to the relief of patient suffering. ${ }^{54}$ Thus, doctors can refuse to comply with certain requests on grounds of personal conscience-for example, if they have a religious objection to the procedure being requested-but doctors can also refuse to perform a certain procedure on grounds of professional conscience, whereby the procedure requested is thought to be incompatible with the proper goals of medicine which the doctor is, or should be, committed to serve.

Although the virtues of professional integrity and conscience can explain why doctors should ensure that their own actions are in accordance with their commitment to proper medical values and goals, what motivates a doctor to blow the whistle on unethical colleagues? Many healthcare whistleblowers say they felt there was no alternative but to make such a public disclosure on discovering a colleague's morally egregious conduct and the lack of interest taken in that conduct by the regulatory authorities. ${ }^{3}$ Turning "a blind eye" to this would make them complicit in both the colleague's wrongdoing, and the harm being done to patients or colleagues.

Virtue ethics provides a strong ethical basis for whistleblowing in health care because it provides a compelling theoretical justification for doctors to report and expose unethical practices. By exposing such practices, a doctor is expressing his or her fundamental commitment in conscience, as a doctor, to the welfare of patients and to the promotion of health and a healthy profession. The reasons why doctors must blow the whistle on wrongdoing are therefore essentially the same reasons why doctors must avoid conflicts of interest-not because of any promises made (which might not cover this situation), nor because this maximises utility (it may not), but because doing otherwise involves a perversion of the fundamental professional virtues that define his or her role as a doctor. ${ }^{11}$

One reason why medical educators may be reluctant to embrace the proposition that whistleblowing has a firm foundation in virtue ethics, relates to the onerous and unfashionable obligations its general endorsement would create among health professionals to profess in public their determination to live a transparently virtuous professional life, and to openly strive to implement the basic spirit of the Hippocratic Oath regardless of obstacles. ${ }^{10} 4354$

\section{TRANSFORMING WHISTLEBLOWING WITH PORTABLE DIGITAL TECHNOLOGY}

One plausible explanation for a decline in willingness to whistleblow in medical trainees, even in the midst of a medical education environment increasingly emphasising virtue ethics, is that theoretically derived principlist ethics taught in an undergraduate curriculum may be seen by such trainees as less relevant to the postgraduate clinical environment, with its different set of practical, clinical priorities and pressures. If this were so, then supporting good reporting behaviour with regard to medical error "at the coalface" would become of paramount importance in addressing the problems created by the "hidden curriculum". 5556

Just as a poor role model can undermine ethical behaviour by eroding belief in the standard to be upheld, so it can be hypothesised that a good role model might improve the ethical behaviour of trainees by reinforcing their convictions concerning the legitimacy of maintaining commitment to the consistent application of ethical principles. ${ }^{54}$ Goldie, in a review of ethics curricula in undergraduate medical education, concluded that some of the most important and effective facilitators of good ethical learning and behaviour are themselves good ethical role models for medical students. ${ }^{57}$ Paice and coauthors confirmed the same finding in interviews with medical graduates. ${ }^{58}$ One plausible conclusion from these studies is that positive role models will encourage good ethical behaviour in young doctors. Why should whistleblowers not be acknowledged as presumptively fulfilling this role? More than that, however, why should we not strive to create incentives for students to see 
themselves as such role models, championing the safety of patients regardless of intrainstitutional obstacles?

Role models of good ethical behaviour seem to be effective not simply by showing what ought to be done in various situations, but also by helping others see why the ethical behaviour is justifiable in the circumstances. A full explanation of how effective good role models can be in terms of encouraging trainees to put their medical ethics education into practice would emphasise the impact that role models typically have on a trainee's character, rather than emphasising merely the impact on the trainee's outward behaviour. Good ethical behaviour is most effectively learnt from doctors who themselves embody the virtue of integrity, where they not only practise themselves what they teach others to do, but also clearly believe in the worth of the standards they are practising and teaching.

A promising way of addressing quality and safety problems in health care aims at creating a technological imperative for practical virtue ethics addressed to the trainee, rather than the senior specialist or academic clinician. ${ }^{3556}$ In conjunction with this, many have suggested that along with good role models ensuring that the working environment of trainees is supportive is vitally important in fostering and reinforcing good ethical behaviour among trainee doctors. Indeed, a recent body of research in social psychology suggests that we tend to overestimate the influence that (at least certain) character traits have on human behaviour, and that relatively minor situational factors influence behaviour far more than is commonly supposed. ${ }^{59}$ Some use these findings to argue that fostering ethical behaviour is as much a matter of removing situational obstacles (such as inconvenience or supervisors who use disclosure to victimise good reporters) to people acting ethically, as it is about inculcating ethically desirable character traits in people. ${ }^{19-21} 60$

The practices and attitudes of trainees in collecting data on their own performance may provide an illuminating example of the importance of role models and environment in developing the virtue of integrity among trainees. Morton emphasised the need for a supportive (not a punitive) environment for the collection of performance data in health care. ${ }^{61} \mathrm{He}$ was commenting on work reported from Geelong Hospital, which has demonstrated the benefits of a supportive environment in the collection and analysis of performance and critical incident data. ${ }^{55662-65}$ Evidence also suggests that the profession can make a difference if its senior members are prepared to set a good example of habituated implementation of ethical principles and design work practices that support good ethical behaviour. ${ }^{64}$ More could be done and we emphasise the profession's moral obligation in this regard.

A personal, professional, performance monitoring programme developed in the Geelong department of perioperative medicine has been used to collect procedural performance data and incident reporting data from anaesthetic trainees in the Australian and New Zealand College of Anaesthetists accredited training posts. ${ }^{55}$

The reported findings were that the registrars were prepared to collect performance data on their own performance..$^{55}$ This is very important if we want to encourage a sense of the professional virtues of conscientiousness and integrity, and with respect to the consistent application of ethical principles in actual day to day medical behaviour. ${ }^{43}$ Secondly, the registrars were prepared to report adverse incidents in their practice even if it involved their own performance. .55666

These two observations represent two important principles for future efforts at ethical behaviour monitoring and improvement. Trainees will collect the correct data in order to successfully optimise their performance and will report adverse events and critical incidents if given simple tools to do so. They will actually tell us about the adverse events that led to adverse outcomes and the adverse events that did not have adverse outcomes. This is the "near miss" data that is the "holy grail" of medical safety and quality improvement. ${ }^{55}$ 66-68

This suggests that despite the possible existence of a hidden counterethics curriculum in medical training, young doctors will, in the right circumstances, not only "make the right decision" but will also then go on to "do the right thing" if given the appropriate technological imperative. In this sense, portable digital technology, with appropriate modifications to its programmes, could be used to assist in developing a practical virtue ethics that supports and values the contributions of whistleblowers to healthcare quality and safety.

A further observation from the anaesthetic department where the personal digital assistant (PDA) system was trialled, is that registrars willingly rely on the performance data as an objective indication of their professional development. They report a high likelihood of collecting the data throughout their specialist careers. ${ }^{69}$ Such observations appear to represent a transformation in the culture of the trainees that can be achieved within a reasonably short period of time. ${ }^{346}$ Our suggestion is that this change involves a metamorphosis of the virtues that encourage whistleblowing into a valuable focus on self reporting and personal and professional development.

In our model, medical students-for example-could be provided with hand held computing devices containing programmes directed to the assessment of, among other skills, basic ethical competencies on the first day of training. They would then be encouraged to record and reflect on the results of their training in a continuous manner. Directed questionnaires would then be sent out periodically and used to guide further training in a similar fashion to the anaesthetic registrar model. ${ }^{55-64}$ In anaesthetics, the specialists can subscribe to the programme and gain continuing medical education (CME) points for a year of data collection. This could be a prerequisite of practice in an organisation or registration in a jurisdiction to encourage an "all win" situation. Certainly the indemnity organisations believe this is one way of reducing indemnity costs: they have thought this for several years now and committed funding to these projects.

These reports of enhanced voluntary performance monitoring, incident, and "near miss" incident reporting using portable digital technology provide the evidence that a practical approach to transforming the virtue ethics foundations of healthcare whistleblowing is achievable in clinical practice. Furthermore, it may encourage needed initiatives in patient safety and healthcare quality. ${ }^{70}$ These may reinvigorate not just medical education but medical professionalism, facilitating the safe delivery of quality health care at reduced cost. $^{71}$ Whether this technology can achieve the necessary culture change in other specialties and with senior specialists will need to be established. ${ }^{64} 72$

\section{CONCLUSION}

Our suggestion is that virtue ethics as a discipline will gain not only by attempting to embrace healthcare whistleblowing within its theoretical foundations, but also through helping to devise systems for improving such whistleblowing in clinical practice. We contend this may be achieved through a practical approach, which encourages the link between professional virtue and conscience and relevant ethical, legal, and international human rights principles and which seeks to habituate the application of such a link through the use of a technological imperative. In a supportive 
institutional environment, nurtured professional virtues, which previously might have spurred healthcare workers to report the quality and safety deficiencies of allegedly impaired colleagues despite institutional resistance, may be transformed into a non-punitive culture of self reporting and professional development using appropriately programmed portable digital technology. ${ }^{63}{ }^{64}$

Exposure to mentoring experiences and medical humanities, which value clinicians willing to "take a stand" for the sake of their patients, should be an important aspect of such a programme. ${ }^{454}$ Related components could involve enhanced testing of ethical attitudes and behaviour in the admissions processes and throughout undergraduate and postgraduate training to identify the parts of the curriculum most and least likely to produce the trainee attitudes that link conscience with healthcare quality and safety. ${ }^{10}$

The goal of such a system of practical virtue ethics is to measure and positively influence consistency in the ethical behaviour of medical undergraduates and postgraduates. It cherishes the virtues expressed by healthcare whistleblowers, while seeking to transform their efforts into a culture of self reporting using the technological imperative provided by portable digital technology. If we can so improve professional character and professional behaviour, we may be able to reduce the burden of the informal counterethics curriculum and its perpetuation of outdated, morally and ethically damaging practices in health care.

\section{Authors' affiliations}

S Bolsin, Division of Perioperative Medicine, The Geelong Hospital, Geelong, Victoria, Australia

T Faunce, Faculty of Medicine and Faculty of Law, Australian National University, Canberra, ACT, Australia

J Oakley, Centre for Human Bioethics, Monash University, Melbourne, Victoria, Australia

\section{REFERENCES}

1 Lennane KJ. "Whistleblowing." A health issue. BMJ 1993;307:667-70.

2 Sibbald B. A right to be heard. Can Nurse 1997;93:22-30.

3 Bolsin SN. Whistleblowing. Med Educ 2003;37:294-6.

4 Faunce T, Bolsin S. Three Australian whistleblowing sagas: lessons for internal and external regulation. MJA 2004:181:44-7.

5 Sibbald B. Twelve deaths in Winnipeg: judge must ponder 48,000 pages of testimony. CMAJ 1998;59:1285-7

6 Kennedy I. The Bristol Royal Infirmary Inquiry, http://www.bristolinquiry.org.uk/index.htm (accessed 17 Mar 2005).

7 Hafferty FW, Franks R. The hidden curriculum, ethics teaching and the structure of medical education. Acad Med 1994;69:861-71.

8 Hundert EM, Douglas-Steele D, Bickel J. Context in medical education: the informal ethics curriculum. Med Educ 1996:30:353-64.

9 Goldie J, Schwartz L, McConnachie A. Students' attitudes and potential behaviour with regard to whistleblowing as they pass through a modern medical curriculum. Med Educ 2003;37:368-75.

10 Rhodes R, Strain JJ. Whistleblowing in academic medicine. J Med Ethics 2004;30:35-9.

11 Faunce T. Developing and teaching the virtue ethics foundation of healthcare whistleblowing. Monash Bioeth Rev 2004;23:41-55.

12 Irvine D. Health service reforms in the United Kingdom after Bristol. MJA 2004;181:27-8.

13 Shorter E. The history of the doctor patient relationship. In: Bynum WF, Porter R, eds. Companion encyclopedia of the history of medicine. Oxford: Brunner-Routledge, 1993:783.

14 Pellegrino ED, Pellegrino AA. Humanism and ethics in Roman medicine: translation and commentary on a text of Scribonius Largus. Lit Med 1988:7:22-6

15 Faden RR, Beauchamp TL, King N. A history and theory of informed consent Oxford: Oxford University Press, 1986:66

16 Wieland W. The concept of the art of medicine. In: Delkeskamp-Hayes C Gardell MA, eds. Science, technology and the art of medicine. Berlin: Kluwer Academic Publishers, 1993:172.

17 Bucknill JC. The medical knowledge of Shakespeare. London: Ams Pr, 1971

18 Carter KS, Abbot S, Siebach JL. Five documents relating to the final illness and death of Ignaz Semmelweis. Bull Hist Med 1995;69:255-70.

19 Firth-Cozens J. Barriers to incident reporting. Int J Qual Health Care 2002;11:7.

20 Firth-Cozens J, Firth R, Booth S. Attitudes to and experiences of reporting poor care. Clinical Governance 2004;8:331-6.
21 Kingston MJ, Evans SM, Smith BJ, et al. Attitudes of doctors and nurses towards incident reporting: a qualitative analysis. MJA 2004;181:36-9.

22 Baker R. Introduction. In: Baker R, ed. The codification of medical morality. Historical and philosophical studies of the formalisation of Western medical morality in the eighteenth and nineteenth centuries. Dordrecht: Kluwer Academic Publishers, 1995:2.

23 Percival T. Medical ethics or a code of institutes and precepts adapted to the professional conduct of physicians \& surgeons [ 1 st ed]. Manchester: J Johnston, 1803.

24 Horner JS. History of medical ethics. In: Chadwick R, ed. Encyclopedia of applied ethics. London: Academic Press, 1998:165-71.

25 Burns C. Reciprocity in the development of Anglo-American medical ethics. In: Baker R, ed. The codification of medical morality. Historical and philosophical studies of the formalisation of Western medical morality in the eighteenth and nineteenth centuries. Dordrecht: Kluwer Academic Publishers, 1995:135-41.

26 Anon. Editorial. BMJ 1896;2:401.

27 Stryrap J. A code of medical ethics. In: Baker R, ed. The codification of medical morality. Historical and philosophical studies of the formalisation of Western medical morality in the eighteenth and nineteenth centuries. New York: Kluwer Academic Publishers, 1995: 149.

28 Nuttall P. The passionate statistician. Florence Nightingale. Nurs Times 1983;79:25-7

29 Monteiro LA. Florence Nightingale on public health nursing. Am J Public Health 1985;75:181-6.

30 Duff E. Florence Nightingale: basing care on evidence. RCM Midwives 1998;1:192-3.

31 Kaska SC, Weinstein JN. Historical perspective. Ernest Amory Codman, 1869-1940. Apioneer of evidence based medicine: the end result idea. Spine 1998;23:629-33

32 Chambler AF, Emery RJ. Lord Moynihan cuts Codman into audit. Ann R Coll Surg Engl 1997;79(suppl 4):174-6S

33 Bolsin SN. After Bristol a positive health management experience-but regretfully not of benefit to British patients. Health Serv J 2001;111:18-19.

34 Higgins J. The listening blank. Health Serv J 2001;111:12-15.

35 Chassin MR, Park RE, Lohr KN, et al. Differences among hospitals in Medicare patient mortality. Health Serv Res 1989;24:1-31.

36 Hannan EL, O'Donnell JF, Kilburn $\mathrm{H}$, et al. Investigation of the relationship between volume and mortality for surgical procedures performed in New York State hospitals. JAMA 1989;262:503-10.

37 McDonald S, Ahern K. Physical and emotional effects of whistleblowing. $J$ Psychsoc Nurs Mental Health Serv 2002;40:14-27.

38 Elek SD. Semmelweis and the oath of Hippocrates. Proc $R$ Soc Med 1966;59:346-52.

39 Duin N, Sutcliffe J. A history of medicine. New York: Barnes and Noble, 1992:54-5.

40 Smith R. All changed, changed utterly. British medicine will be transformed by the Bristol case. BMJ 1998:316:1917-18.

41 Thorwald J. The century of the surgeon. London: Pan, 1957:195-208.

42 Bolsin SN. Personal perspective. Professional misconduct: the Bristol case. Med J Aust 1998; 169:369-72.

43 Faunce T, Bolsin SN, Chan W-P. Supporting. whistleblowers in academic medicine: training and respecting the courage of professional conscience. $J$ Med Ethics, 2004;30:40-3.

44 Rees-Mogg W. Why did they allow so many to die? The Times 1996;Apr 1: 21.

45 Horton R. Yesterday's doctors. Lancet 1998;352:1566-7.

46 Horton R. How should doctors respond to the GMC's judgments on Bristol? Lancet 1998;351:1900-1.

47 Horton R. UK medicine: what are we to do? Lancet 1998;352:1 166

48 Horton R. Doctors, the General Medical Council, and Bristol. Lancet 1998;351:1525-6.

49 Smith R. Repositioning self regulation. The influence of the GMC may be leaking away. BMJ 1998;317:964.

50 Wolf TM, Balsom PM, Fawcett JM, et al. A retrospective study of attitude change during medical education. Med Educ 1989;23:19-23.

51 Rennie SC, Crosby JR. Student's perceptions of whistleblowing: implications for self regulation. A questionnaire and focus group survey. Med Educ 2002;36:113-14.

52 Pellegrino ED. Toward a virtue based normative ethics for the health professions. Kennedy Inst Ethics J, 1995;5:253-74.

53 Cocking D, Oakley J. Medical experimentation, informed consent and using people. Bioethics 1994;8:293-311.

54 Faunce T. Pilgrims in medicine: conscience, legalism and human rights. An allegory of medical humanities, foundational virtues, ethical principles, law and human rights in medical personal \& professional development [ $1 \mathrm{st}$ ed] Leiden, The Netherlands: Koninklijke Brill NV, 2005.

55 Bent $\mathrm{P}$, Creati $\mathrm{B}$, Bolsin SN, et al. Professional monitoring and critical incident reporting using personal digital assistants. MJA 2002;177:496-9.

56 Bolsin SN, Solly R, Patrick A. The value of personal professional monitoring performance data and open disclosure policies in anaesthetic practice: a case report. Int J Qual Health Care 2003;12:295-7.

57 Goldie J. Review of ethics curricula in undergraduate medical education. Med Educ 2000;34:108-19.

58 Paice $E$, Heard S, Moss F. How important are role models in making good doctors? BMJ 2002;325:707-10.

59 Ross L, Nisbett R. The person and the situation: perspectives of socia psychology. New York: McGraw-Hill, 1991.

60 Doris JM. Lack of character: personality and moral behaviour. New York: Cambridge University Press, 2002. 
61 Morton A. The use of statistical process control methods in monitoring clinical performance. Int J Qual Health Care 2003;15:361-2.

62 Bolsin SN, Colson M. Methodology matters: CUSUM. Int J Qual Health Care 2000;12:433-8.

63 Bolsin S. Routes to Quality Assurance: Risk adjusted outcomes and personal professional monitoring. Int J Qual Health Care 2000;12:367-9.

64 Bolsin SN, Colson M. Making the case for personal professional monitoring in health care. Int J Qual Health Care 2003;15:1-2.

65 Bolsin S, Colson M. The use of statistical process control methods to monitor and improve clinical performance. Qual Safe Health Care 2003;15:445.

66 Bolsin S, Patrick A, Creati B. Electronic incident reporting and professional monitoring transforms culture. BMJ 2004;329:51-2.
67 Vincent C, Taylor-Adams S, Stanhope N. Framework for analysing risk and safety in clinical medicine. BMJ 1998;316:1154-7.

68 Reason J. Human error: models and management. BMJ 2000;320:768-70.

69 Bolsin SN. League tables and professionalism. Aust Health Rev 2001:24:1-4.

70 Oakley J. A virtue ethics approach. In: Kuhse H, Singer P, ed. A companion to ethics. Oxford: Blackwell, 1998:86-97.

71 Kohn CT, Corrigan JM, Donaldson MS. To err is human. Building a safer health system. Washington: Institute of Medicine, 1999:1-16.

72 Bolsin S, Colson M. The use of statistical process control methods in monitoring clinical performance. Int J Qual Health Care 2003;15:445.

Notice

Increasing Ethics, Communication, and Social Science Content for Written Exams in Undergraduate Medicine

Hosted by the Universities Medical Assessment Partnership (UMAP), this is a workshop to disseminate good practice in question writing whilst also helping to incorporate ethics, communication, and social science questions into the UMAP bank. This will serve to encourage these topics to be assessed at UMAP partner medical schools who at present include Newcastle, Leeds, Liverpool, Manchester, and Sheffield.

Date: Thursday $24^{\text {th }}$ November 2005

Timings: Workshop $11.00-1.30 p m$; Lunch 1.30pm; Workshop $2.30-5.00 p m$

Place: Gartree and Rutland, $4^{\text {th }}$ Floor, Charles Wilson Building, Leicester University

Presenter: Andrea Owen, UMAP Project Manager

Places are free of charge and can be booked by contacting the UMAP office by email, umap@fs1.with.man.ac.uk or telephone, 0161291 5805. See the project website for more details www.umap.man.ac.uk 